\title{
Ruptura atraumática de baço: relato de caso
}

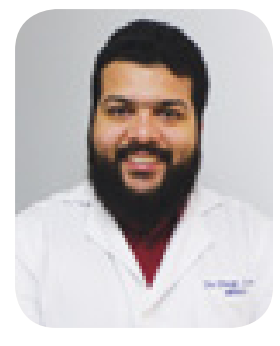

Diêgo Venicio Santos Argôlo', Elves Maciel'1, Edson Marques Filho'.

O primeiro relato de ruptura esplênica espontânea foi descrito em 1874, por Atkinson ${ }^{1}$, no entanto, pouco se sabe sobre as principais características dos pacientes que sofrem desta entidade, e há uma dificuldade na pesquisa do tema, devido à falta de padronização na nomenclatura. Alguns autores sugerem que a ruptura espontânea, ou também chamada atraumática, de um baço já enfermo seja chamada "Ruptura Patológica", em uma referência às doenças ósseas malignas que cursam com fratura. Assim, o termo "Ruptura Espontânea ou Atraumática" seria reservado aos casos nos quais o baço é saudável.

É uma condição rara, com uma revisão sistemática da literatura até 2008, revelando 845 casos descritos $^{2}$, porém grave e com risco elevado de óbito e complicações, principalmente quando não diagnosticada ou tardiamente identificada. O presente relato de caso tem o intuito de chamar atenção para as principais características dos pacientes que apresenta, essa é a condição para que essa hipótese seja afastada na abordagem inicial desses pacientes.

\section{RELATO DE CASO}

Paciente masculino, 65 anos, em acompanhamento oncológico por linfoma de manto estadio IV, portador de doença pulmonar obstrutiva crônica, foi admitido na emergência com queixa mal-estar súbito, enquanto dirigia, acompanhado de náuseas, vômitos e sudorese. O paciente encontrava-se pálido, sem outras queixas ou achados na admissão, pressão arterial 110x60 mmHg, frequência respiratória 18ipm, frequência cardíaca $88 \mathrm{bpm}$.

Após a admissão, o paciente evoluiu com hipotensão e taquicardia, feita expansão volêmica com $1.000 \mathrm{ml}$ de solução cristaloide, com resposta parcial, requerendo infusão de noradrenalina. Foi feita suspeita inicial de sepse, devido à presença de sinais de resposta inflamatória sistêmica (SIRS), e iniciado protocolo institucional específico, que compreende coleta lactato, culturas e an- tibioticoterapia precoce, além de expansão volêmica em caso de hipotensão ou elevação do lactato. Os exames laboratoriais iniciais chamavam a atenção por lactato 1,4, BE -2,2, leucócitos $19.940 / \mathrm{mm}$, plaquetas 64.000, hemoglobina 9,3 , creatina 1,52 , ureia 46,9 , sem outras alterações significativas. Foram iniciados metronidazol e ceftriaxona, por suspeita de sepse de foco gastrointestinal e encaminhado à Unidade de Tratamento Intensivo (UTI) Cirúrgica Adulto do HSI.

Ao ser admitido na UTI, paciente encontrava-se em uso de Noradrenalina $0,03 \mathrm{mcg} / \mathrm{kg} / \mathrm{h}$, lúcido e orientado, abdome flácido, doloroso à palpação, difusamente sem sinais de peritonite, com massa palpável em hipocôndrio esquerdo. Mantida antibioticoterapia e solicitados exames admissionais.

Nos exames notou-se a queda da hematimetria $(\mathrm{Hb}$ $6,4)$ e plaquetopenia $(54.000)$, sem que houvesse exteriorização de sangramento. Solicitada realização de endoscopia digestiva alta (EDA) de urgência e transfusão de dois concentrados de hemácias. Resultado da EDA revelou angiectasia gástrica sem sangramento ativo.

Paciente evoluiu com melhora da dor e desmame da noradrenalina, suspenso o metronidazol. Realizada tomografia (TC) de abdome, pela suspeita de sangramento abdominal, que evidenciou aumento difuso e heterogêneo no parênquima esplênico, com pequena quantidade livre (sangue) na cavidade abdominal (fig. 1), com pequenas áreas hipodensas sugestivas de contusão ou infarto. $\mathrm{O}$ cirurgião foi consultado e adotou conduta conservadora incialmente, mantendo-o em vigilância pelo risco de ressangramento.

Paciente submetido à abordagem eletiva sete dias após a admissão, após discussão conjunta do caso com a cirurgia, considerando o risco de ruptura franca e ressangramento, além da plaquetopenia possivelmente associada a sequestro esplênico e possivelmente baço não funcional. No pós-operatório imediato, o paciente evoluiu com hipotensão refratária, não condizente com a evolução 
esperada, somado a um quadro de íleo adinâmico. Identificada a formação de um abscesso em loja esplênica após $72 \mathrm{~h}$ do pós-operatório, escalonado antibiótico para Tazocin, coletadas novas culturas e encaminhado para drenagem do abscesso. Recuperou-se bem e recebeu alta da UTI 17 dias após admissão e hospitalar após 18 dias da alta da UTI.

\section{DISCUSSÃO}

A queixa mais comum nos casos de ruptura esplênica atraumática é a dor abdominal em quadrante superior acompanhada de hipotensão ortostática. Em uma revisão realizada por Kianman et. al. ${ }^{3}$, mostrou que aproximadamente 1/3 dos pacientes apresentam-se chocados na admissão e até $8 \%$ morrem antes mesmo de serem abordados.

Em 2009, Renzuli e cols. encontraram uma predominância de 2:1 em homens, média de idade de 46 anos, sendo o principal fator etiológico a presença de doença hematológica maligna $(16,4 \%)$, seguido de infecções virais e doença inflamatória local (pancreatite aguda e crônica). Foi encontrada ainda uma mortalidade de $12,2 \%$ em pacientes com mais de 40 anos. E com esplenomegalia ao diagnóstico possivelmente há maior risco de desfecho desfavorável ${ }^{3}$.

Há nos exames de imagem um papel fundamental, na radiografia de abdômen, os achados são inespecíficos: esplenomegalia, aumento da hemicúpula diafragmática, deslocamento da bolha gástrica. Tendo uma sensibilidade de $95 \% 4$, a TC de abdome é o exame de escolha para esses casos, podendo ser observada à existência de hematoma ou ruptura, bem como graduá-la e evidenciar a presença ou não de sangramento abdominal, ajudando na conduta terapêutica. A desvantagem da TC está na necessidade de estabilidade hemodinâmica para o transporte do paciente. Quando há instabilidade hemodinâmica, a realização do FAST (Focused Abdominal Sonographic Technique) costuma ser uma boa indicação: exame à beira leito, rápido, fácil e não invasivo. Porém, é operador dependente e possui baixa sensibilidade para sangramentos menores que $200 \mathrm{ml}$.

O caso apresentado ressalta a dificuldade diagnóstica, uma vez que, habitualmente, não se considera ruptura esplênica sem história de trauma associado. Entretanto, consideramos que a presença de queda de hemoglobina clinicamente significativa (hipotensão e necessidade de hemotransfusão), sem exteriorização de sangramento, obrigatoriamente indica exames de imagem para afastar sangramento (de órgão sólido, livre abdominal ou retroperitoneal). Além disso, enfatizamos o risco do uso de protocolos "rígidos", sem o devido julgamento clínico. A sín- drome séptica é caracterizada por um conjunto de sinais e achados laboratoriais inespecíficos, que, se aplicados ao paciente gravemente enfermo, sem uma avaliação cuidadosa da história e antecedentes, pode levar a um diagnóstico errôneo e, por conseguinte, manejo inadequado.

Vencido o primeiro obstáculo, pensar em ruptura esplênica espontânea, o diagnóstico pode ser feito com grande acurácia com exame tomográfico. $\mathrm{O}$ segundo ponto críti$\mathrm{co}$, nessa patologia, é o manejo.

A despeito do avanço nos exames de imagem e possibilidade de tratamento conservador nas lesões esplênicas traumáticas, em até $60 \%$ dos casos, lesões do baço ainda representam a razão mais comum para laparotomia por lesão traumática de órgão sólido abdominal. ${ }^{5}$

A revisão sistemática da literatura sugere que a conduta baseada na escala de trauma esplênico, elaborada pelo colégio americano de cirurgiões, não tenha grande utilidade nesses casos, tendo a etiologia da rotura um papel importante na tomada de decisões. Isso é baseado no achado que pacientes com uma doença hematológica diagnosticada parecem ter um desfecho pior. Além de que, pacientes submetidos à conduta conservadora, que precisaram de uma abordagem cirúrgica posterior, tiveram um aumento na mortalidade.

Nesses casos, a conduta é "cirúrgica" quando o paciente é submetido à esplenectomia nas primeiras $24 \mathrm{~h}$ do diagnóstico. Passado esse tempo, entende-se como "conservadora". Não há um consenso quanto à melhor abordagem para esses pacientes. Na presença de hemoperitônio e choque refratário, a esplenectomia de urgência é a conduta de escolha. Nos pacientes estáveis e com sangramento contido, segundo Renzuli2, há pouco sucesso na conduta conservadora. Parece haver melhor resultado quando a esplectomia é realizada no momento do diagnóstico, quando há uma doença hematológica maligna como fator etiológico.

A escolha por uma abordagem cirúrgica, mesmo quando hemodinamicamente estável, parece se justificar devido à possibilidade de confirmação etiológica na peça anatômica retirada, já que um grande número de doenças malignas, pode causar ruptura atraumática do baço, impossibilitando a preservação do órgão. Por fim, a função esplênica já se encontra prejudicada em muitos casos, podendo levar a complicações outras, além da ruptura em si.

Habitualmente, casos de ruptura esplênica apresentam-se com sinais de gravidade, o que costuma levar a admissão em UTI, onde o diagnóstico correto e manejo adequado são essenciais nessa condição de elevada letalidade ${ }^{2}$. Por isso, o emergencista e o intensivista devem considerar a ruptura esplênica atraumática no diagnóstico diferencial de pacientes com choque e evidência indireta 
de sangramento, especialmente em pacientes com patologias esplênicas prévias, para que o tratamento correto possa ser instituído, evitando desfechos desfavoráveis.



Figura 1 - Corte Coronal e Sagital da TC realizada no $2^{\circ}$ dia de internação, demonstrando esplenomegalia acompanhada de áreas hipodensas sugestivas de sangramento e infarto esplênico.

\section{REFERÊNCIAS}

1. Atkinson $E$. Death from idiopathic rupture of the spleen. BrMed J 1874;/2:/4034.

2. P. Renzulli, A. Hostettler, A. M. Schoepfer, B. Gloor and D. Candinas Atraumatic splenic rupture. British Journal of Surgery 2009; 96: 1114-1121.

3. R. Kianmanesh, et al. Spontaneous splenic rupture: Report of three new cases and review of the litterature. Ann Chir2003;128:303 9.

4. Jeffrey RB, Laing FC, Federle MR. Computed tomography of splenic trauma. Radiology 1981;/141:/729.

5. Trauma, 8e Moore EE, Feliciano DV, Mattox KL. Moore E.E. Trauma, Eighth Edition Copyright @ 2017 by McGraw-Hill Education.

6. Jeffrey RB, Laing FC, Federle MR. Computed tomography of splenic trauma. Radiology 1981;/141:/729.

1- Serviço de Medicina Intensiva do HSI

Endereço de correspondência:

dvsargolo@gmail.com 